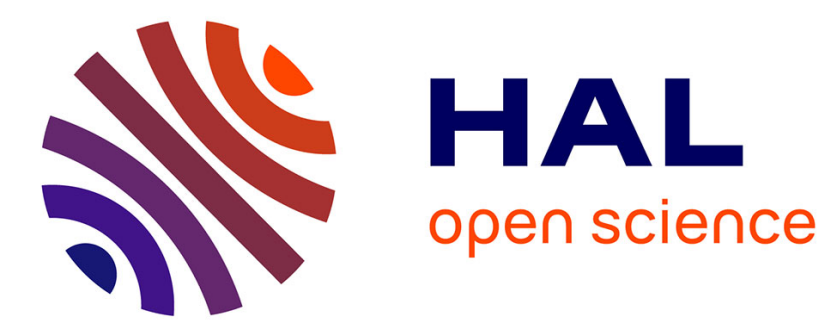

\title{
Validation of the driver ecological glare test
}

\author{
Julien Adrian, David Hue, Sophie Porte, Johan Le Brun
}

\section{To cite this version:}

Julien Adrian, David Hue, Sophie Porte, Johan Le Brun. Validation of the driver ecological glare test. Journal of Safety Research, 2020, 72, pp.139-143. 10.1016/j.jsr.2019.12.007 . hal-02874800

\section{HAL Id: hal-02874800 \\ https://hal.sorbonne-universite.fr/hal-02874800}

Submitted on 19 Jun 2020

HAL is a multi-disciplinary open access archive for the deposit and dissemination of scientific research documents, whether they are published or not. The documents may come from teaching and research institutions in France or abroad, or from public or private research centers.
L'archive ouverte pluridisciplinaire HAL, est destinée au dépôt et à la diffusion de documents scientifiques de niveau recherche, publiés ou non, émanant des établissements d'enseignement et de recherche français ou étrangers, des laboratoires publics ou privés. 


\section{Validation of the Driver Ecological Glare Test}

Julien Adrian ${ }^{\mathrm{a}}$, David Hue ${ }^{\mathrm{b}}$, Sophie Porte ${ }^{\mathrm{b}}$, Johan Le Brun ${ }^{\mathrm{a}}$

${ }^{\text {a }}$ Streetlab, Institut de la Vision, Paris, France

${ }^{b}$ Valeo Lighting Systems, Bobigny, France

\section{${ }^{*}$ Corresponding author:}

Julien Adrian

Streetlab, 17 rue Moreau, 75012 Paris, France

Tel.: +33153462643

E-mail: julien.adrian@streetlab-vision.com

Keywords : disability glare, driving, glare test, ADAS validation

Declarations of interest: This research was supported by Valeo 


\section{Abstract}

The present study proposes to validate the Driver Ecological Glare Test (DEGT), a test developed to measure the benefit of a headlight glare Advanced Driver Assistance System (ADAS), by comparing it to a laboratory glare test. Twenty-four participants, aged from 55 to 70 years, were recruited to complete a visual examination, including monocular halo size measurement for both eyes using Vision Monitor device (MonCv3; Metrovision). An on-field evaluation took place at night at the UTAC CERAM test track to obtain disability glare measures using the DEGT. A significant correlation was found between the two glare tests and Bland-Altman analysis reveals a good agreement with a bias of 73.7 arcmin between the halo size measurements obtained from the DEGT and Vision Monitor. The results of the present study demonstrate that the DEGT is a valid method to test halo size and is adapted to evaluate the benefits of an antiglare device for drivers in an ecological situation.

Keywords: Glare; Driving Glare test Driving; disability glare; halo size measurement 


\section{Introduction}

Driving at night is particularly challenging because of glare produced by headlamps of oncoming vehicles. Headlamp glare produces discomfort leading many older drivers to limit, or completely stop, driving at night. It can also lead to difficulties performing certain visual tasks related to driving, such as detecting pedestrians (Wood et al., 2012), detecting objects or hazards on the road and following the traffic lane (Akashi \& Rea, 2001; Ranney, Masalonis, \& Simmons, 1996; Theeuwes, Alferdinck, \& Perel, 2002). Glare from oncoming headlights has also been associated with night time traffic accidents (J. Bullough et al., 2008; Plainis, Murray, \& Charman, 2005).

According to the CIE, glare is a condition of vision in which there is discomfort or a reduction in the ability to see details or objects, caused by an unsuitable distribution or range of luminance, or by extreme contrasts. Glare can be categorized into Discomfort Glare and Disability Glare. Discomfort glare is defined as 'glare that causes discomfort without necessarily impairing the vision of objects'. Discomfort glare causes annoyance, fatigue or pain without necessarily affecting visibility and can lead to distraction (Bullough, Fu, \& Van Derlofske, 2002; Mainster \& Timberlake, 2003). Disability Glare is defined as, 'glare that impairs the vision of objects without necessarily causing discomfort'. Disability Glare is caused by the diffusion of bright light inside the eye (Miller \& Benedek, 1973; van den Berg et al., 2009) creating a more or less important veil, or disk halo around the glare source, that reduces retinal contrast across the visual field. This loss of contrast is greater in dark (scotopic, mesopic) rather than bright (photopic) environments because rod photoreceptors, that allow night vision, require greater differences in contrast for target detection than cones, that allow day vision (about $20 \%$ vs $1 \%$, respectively) (Wördenweber, Wallaschek, Boyce, \& Hoffman, 2007). The handicap resulting from glare gets larger as the intensity of the light increases and the fixation point of the driver gets closer to the source of glare (Bullough et al., 2008; Vos, 2003). This can result in the driver being unable to see obstacles or hazards 
on the road. Disability glare can be assessed by measuring the size, in visual angle, of the glare halo produced by a glare source (Puell, Pérez-Carrasco, Barrio, Antona, \& PalomoAlvarez, 2013).

The glare while driving problematic has led to a large amount of work and development to provide countermeasures or Advanced Driver Assistance Systems (ADAS) to reduce glare. In order to evaluate the effectiveness of these systems there are only a few tools and the most commonly used of them, the de Boer scale (De Boer, 1967), only deals with discomfort glare. Conversely the evaluation of disability glare while driving seems more complex to evaluate and to our knowledge no test allows an objective evaluation of the visual deficit (halo size measure) caused by these situations. There are methodologies, often complex in their implementation, to evaluate pedestrian detection time while driving (Clark, 2004; Whetsel Borzendowski, Stafford Sewall, Rosopa, \& Tyrrell, 2015). However, these methods do not provide a perfect measure of driver vision, since this measure of glare can be strongly influenced by other driver characteristics, such as individual differences in reaction time, visual adaptations or tactical compensations (lateral positioning or driving speed). Thus, individual driver characteristics that are not directly relevant for glare measurement will constitute a measurement error. This weakness means that the measures obtained are likely to be heterogeneous and therefore less sensitive. While those methods are, to a large extent, ecological they are nevertheless not fully adapted to ADAS validation.

The objective of this study is to validate a new method for evaluating Advanced Driver Assistance Systems (ADAS) dedicated to headlight glare reduction.

Our field test, the Driver Ecological Glare test, was developed to calculate a halo size measurement. To develop our test, we started from the most ecological driving glare situation and we also based ourselves on the classic glare sensitivity tests performed in clinical examinations such as the Nyktotest (Rodenstock GmbH, Ottobrun, Germany), and the Mesotest (Oculus $\mathrm{GmbH}$, Wetzlar, Germany). To validate our test we needed a reference test which is the Vision Monitor device from Metrovision (Palomo-Álvarez \& Puell, 2015; 
Puell et al., 2013; Puell, Pérez-Carrasco, Palomo-Alvarez, Antona, \& Barrio, 2014). However, in order to evaluate the real effectiveness of an anti-glare device, we wanted to adapt our test so that it would be more ecological, that is closer to the real conditions experienced by a driver in a glare situation. Furthermore, the DEGT must allow the evaluation of the benefit of a device to be tested without observing a floor or ceiling effect.

The methodology consists of comparing the results obtained by the participants during the DEGT with those obtained during the laboratory-based glare test using the Métrovision tool.

\section{Methods}

\subsection{Participants}

Twenty four participants, 7 women and 17 men, aged from 55 to 70 years (mean 64.12 , SD 5.10) were recruited in the community and gave informed consent to participate in this study. They were glare sensitive, in good general health, fluent in French and were licensed drivers. Participants with an abnormal visual deficit or cognitive deficit were excluded. Participants received compensation for participating. To capture the demographic a questionnaire was filled out during the recruitment period.

\subsection{Testing Procedure}

All participants first passed an ophthalmologic assessment in a visual examination room. Participants were clinically evaluated for their visual acuity, contrast sensitivity, visual field and stereoscopy. Cognitive screening was also realized and all participants scored high on the Mini Mental State Exam (MMSE) and above the cut off score of 27 indicating intact normal cognitive functioning.

The Vision Monitor (MonCv3; Metrovision, Pérenchies, France) measures the size of halos. Glare is produced by two white circular light sources (LEDs) on each side of the device, each emitting a luminance of $200,000 \mathrm{Cd} / \mathrm{m} 2$. The visual angle of each source from the center of 
the monitor, at a distance of $2.5 \mathrm{~m}$, is 3.8 degrees. At this distance, the illumination of the eye produced by the glare source is 7 lux. Each eye is tested individually with the glare source on the same side as the eye being tested. The optotypes that the subject must read under glare conditions consists of letters having a size of 15 arcmin at a distance of $2.5 \mathrm{~m}$ corresponding to a decimal visual acuity of $0.33(+0.5 \log M A R)$. These optotypes are arranged in three radial lines of letters appearing from the periphery towards the glare source. Each line contains 10 letters spaced by a 33 arcmin interval. Two different letter combinations are used. The optotypes are presented on a dark background with one of three luminance levels: 1,5 and $100 \mathrm{~cd} / \mathrm{m} 2$. In this study, the test was performed using a letter luminance level of 5 $\mathrm{cd} / \mathrm{m} 2$. This level is at the upper end of the mesopic range, the luminance ratio (LmaxLmin)/Lmin for this level being 40.7 .

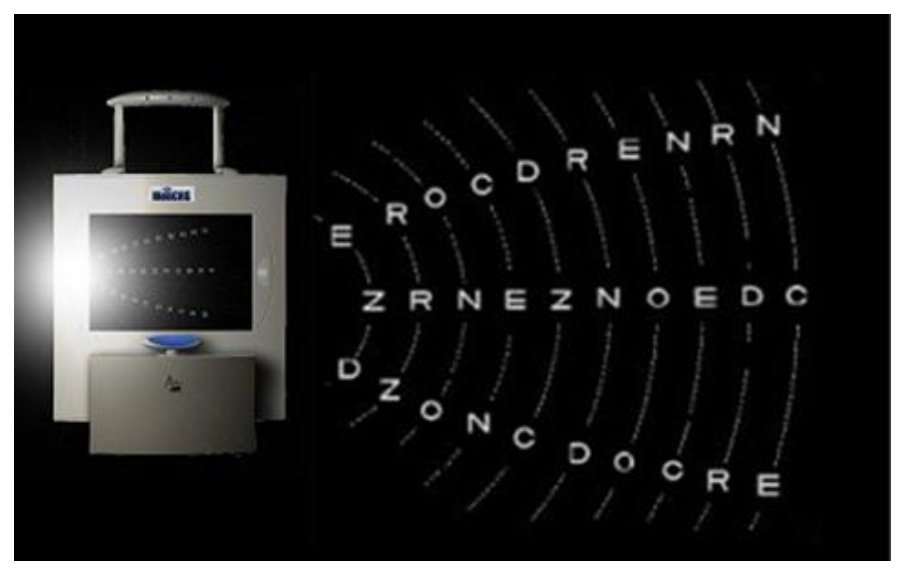

Fig 1. Vision Monitor. Mon CV3; Metrovision glare test

Halo size was measured for optotypes in the central lines of letters appearing from the periphery toward the glare source. Since the test was passed in a monocular condition, as is the case for the glare tests in the ophthalmic evaluation, we chose to keep only the value of the best eye since it is this one which will determine the threshold in binocular vision.

The on-field evaluation took place at the UTAC CERAM test track, in France, during night time hours from $9 \mathrm{pm}$ to midnight between mid-February and mid-march. The choice for 
using a test track was the reproducibility of the data and the possibility to perform the visual test without any traffic or external light. The results presented in this paper are part of a larger study in which we conducted circuit tests.

\subsection{The Driving Ecological Glare Test}

The DEGT measures the size of the glare halo produced by the headlamps of an opposing car at night time. It is inspired from the glare test developed by Metrovision on the MonPackOne Vision Monitor device.

The test must be performed in an environment without any light pollution. The participant is seated in a stationary car in the driver's seat. A static opposing car positioned at $50 \mathrm{~m}$ distance produces an illumination of 7.8 Lux on the subject (measured at the head position of the participant).

A chart of 10 optotypes, arranged in a horizontal line, is placed near the opposing car at the same height as the headlamps. Optotypes are E of Raskin arranged on a chart with four different orientations. All optotypes are the same size and each bar of the $E$ of Raskin measures $42.5 \mathrm{~mm}$, corresponding to a visual acuity of about $+0.5 \log \mathrm{MAR}$.

The first optotype of the chart is placed at 60 arcmin (1 degree) from the headlamp of the opposing car. The optotypes are spaced equally from each other by 30 arcmin ( 0.5 degrees).

Optotypes all have the same light color and the background is dark. The chart is illuminated by the low beam headlamps of the subject's car. The mean luminance of the optotypes is $1.57 \mathrm{Cd} / \mathrm{m}^{2}$ and the mean luminance of the background is $0.37 \mathrm{Cd} / \mathrm{m}^{2}$.

For each trial, a new series of optotypes are presented.

The participant has to read, with both eyes open, the most optotypes possible starting from the greatest eccentricity. Before every trial, the participant is adapted for 5 minutes to 
mesopic conditions. The variable measured in the DEGT concerns the size of the halos (in arcminutes) produced by the glare.

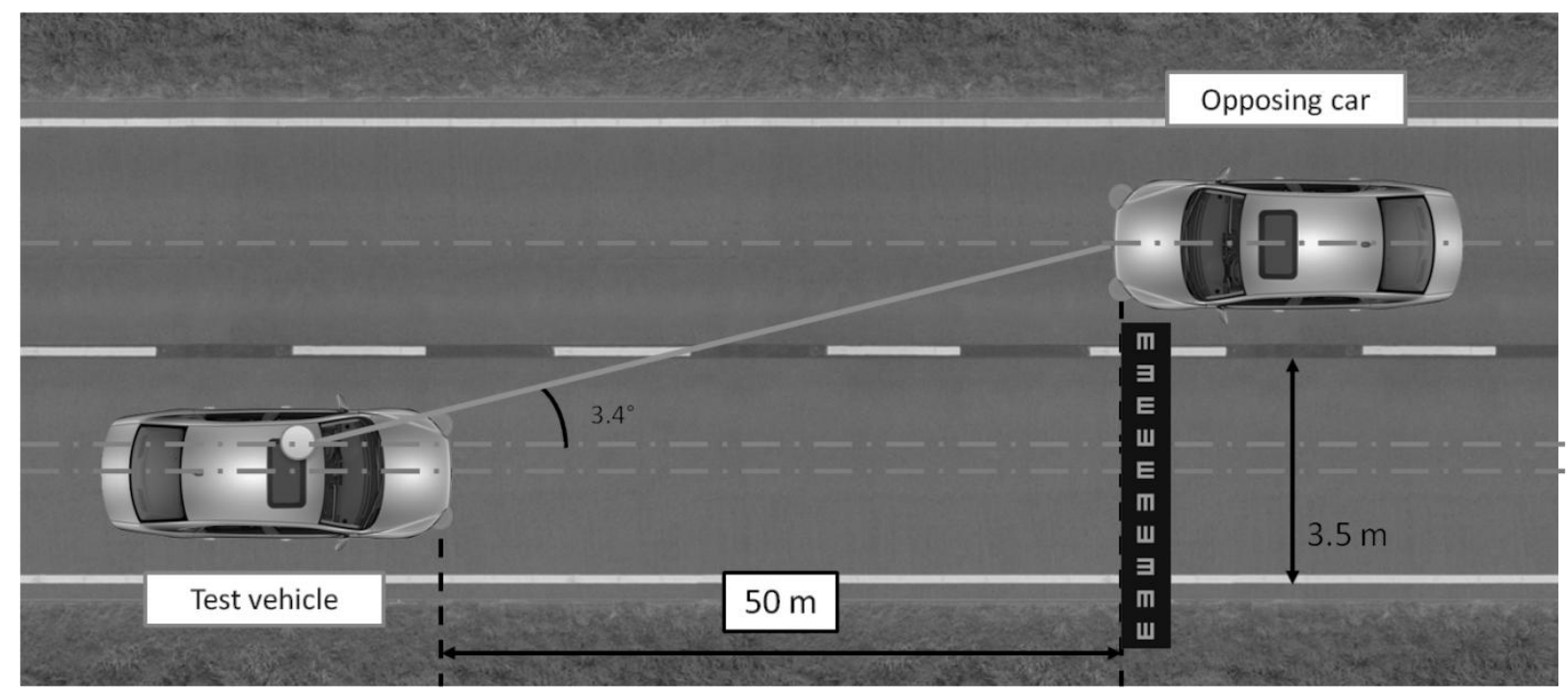

Fig. 2. Diagram showing how the visual angle produced by the radius of the halo is determined.

\subsection{Statistical procedures}

Statistical tests were performed using XLSTAT and MedCalc statistical software.

Significance for all statistical tests was set at a P value of less than .05 . The correlation and the amount of variance shared by the Vision Monitor (Metrovision) and the DEGT measures was assessed using simple linear regression. According to Cohen's criteria (1992) we considered effect size correlations between .1 and .3 as "small", those between .3 and .5 as "medium" and those over .5 as "large". Shapiro-Wilk was used to test the normality of residuals.

Bland-Altman analysis was used to measure the agreement between the two glare tests with $95 \%$ limits of agreement (mean difference \pm 1.96 standard deviation). As the Bland-Altman limits of agreement requires that the differences are normally distributed we have conducted 
a Shapiro-Wilk test to assess normality. Student's t test was also used to establish the significance of the differences observed.

\section{Results}

The mean halo radius was $126.25 \pm 60.63$ arcmin (range: 60.0 to 270.0 arcmin) for the Vision Monitor device. The mean halo radius was $200.00 \pm 57.10$ arcmin for the DEGT.

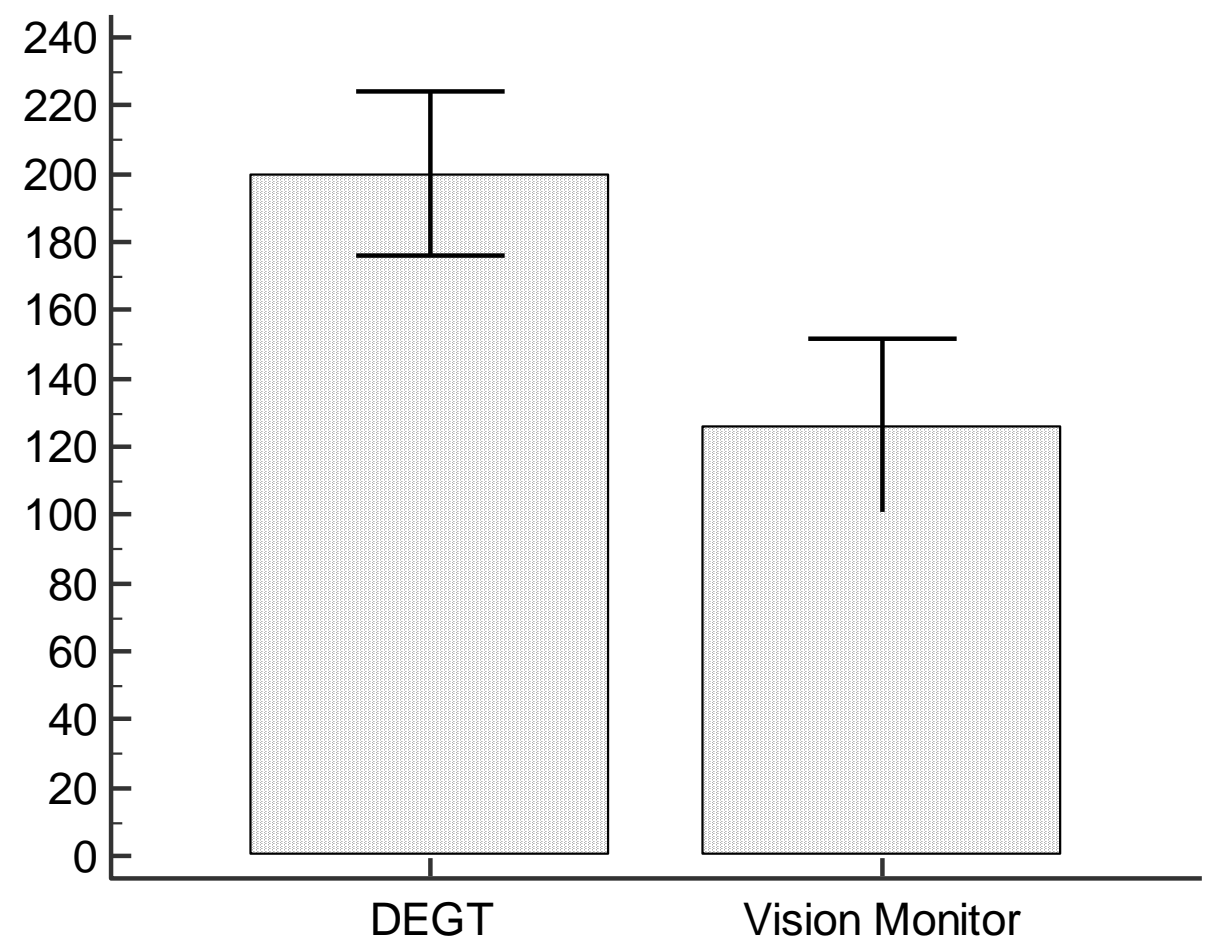

Fig 3. Mean halo radius for the Vision Monitor and driver ecological glare test. Vertical lines indicate the $95 \% \mathrm{Cl}$.

Linear regression analysis performed on the DEGT as a function of the Vision Monitor measures for the best eye are presented in figure 4 .

The results of the simple linear regression indicated that the DEGT score was significantly correlated with the laboratory-based test $(r=.697 ; \mathrm{p}<.001)$. According to Cohen's classification, the correlation observed is of a "large" size. The result of the regression 
indicated that the two glare tests share $48,6 \%$ of the variance $\left(R^{2}=.486, F(1,21)=19.883\right.$, $p<.001)$

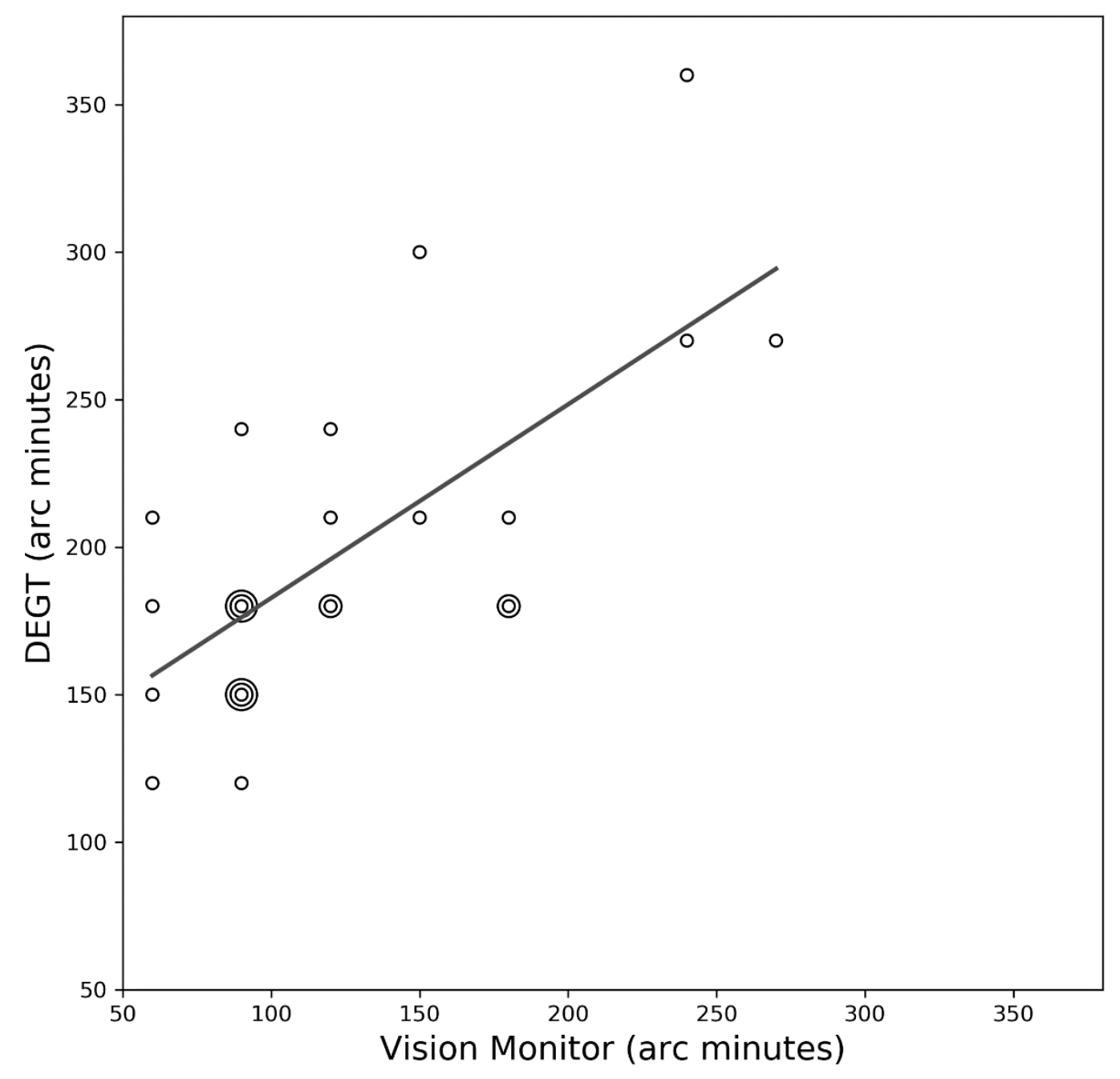

Figure 4 Correlation between the Vision Monitor and the Driver Ecological Glare test. Concentric circles were used for multiple points in the same coordinate. Each circle represents a coordinate. 
The residual plot (figure 5.) show a fairly random pattern indicating that the linear model provides a decent fit to the data and that no residuals are out of the range $[-2,2]$. The Shapiro-Wilk test show that the residuals were normally distributed $(W=.954, p=.323)$.

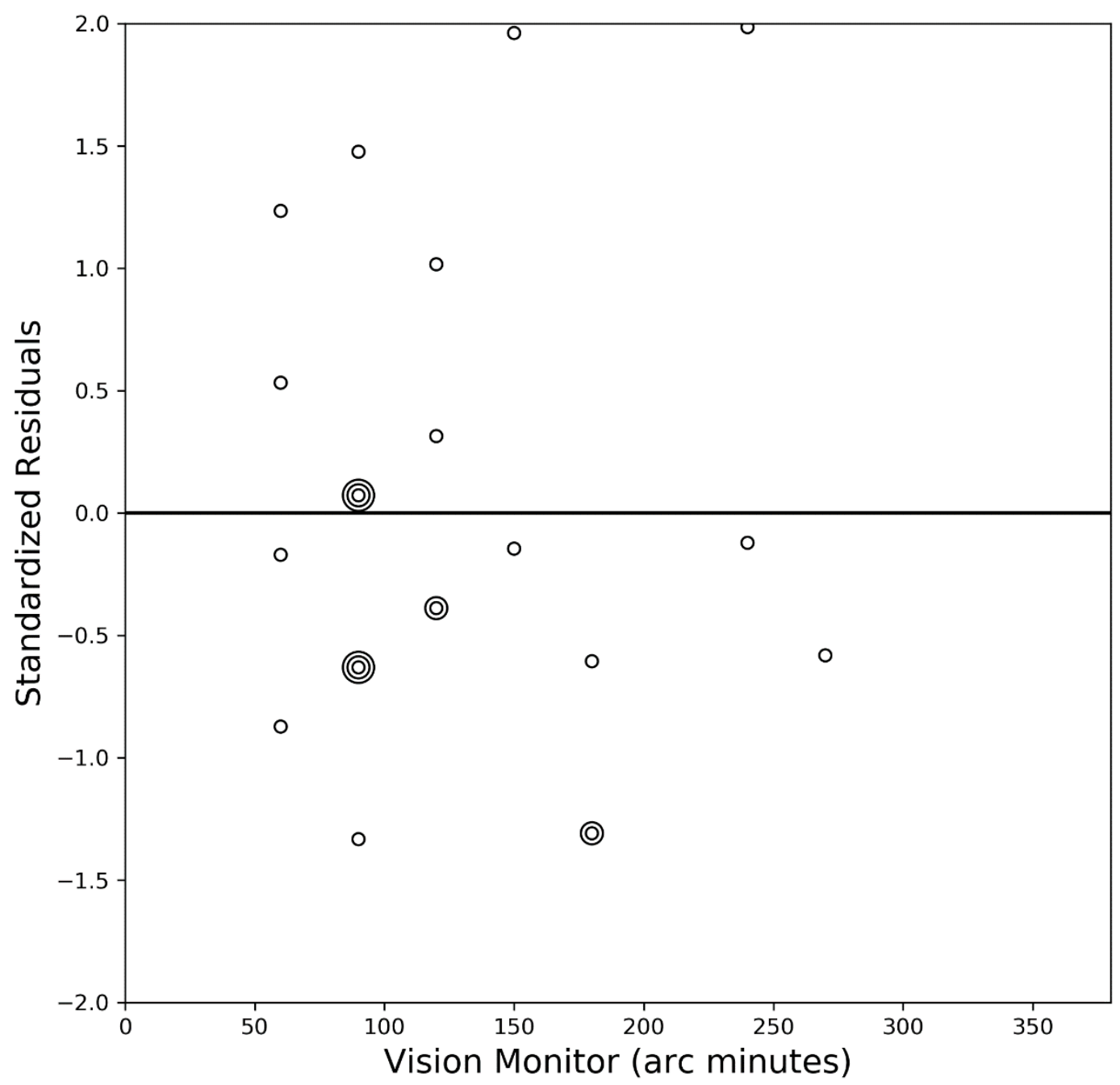

Figure 5. Scatter plot of the standardized residuals vs. vision monitor scores. Concentric circles were used for multiple points in the same coordinate. Each circle represents a coordinate. 
The level of agreement was further assessed through Bland-Altman plots. the Shapiro-Wilk test indicated that the differences were statistically normally distributed ( $p>05)$. In Figure 6 Bland-Altman plots are represented by means of the difference between the two methods [DEGT - Vision Monitor] against the mean [(DEGT+ Vision Monitor)/2]. The graphic analysis shows that the bias was constant. All the subject data is within the limit of agreement. Thus, the DEGT shows comparable results.

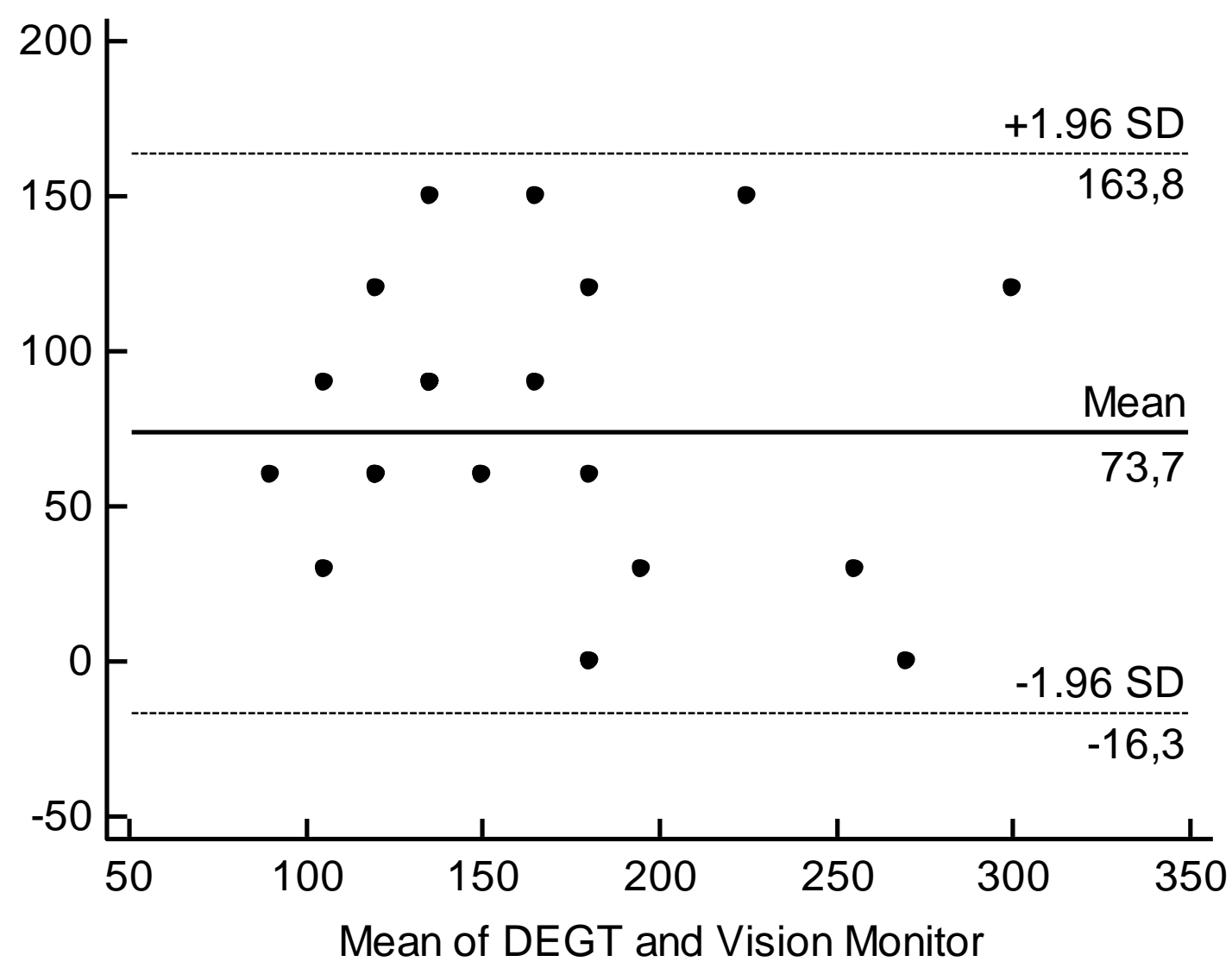

Fig 6. Bland-Altman plot of the relation between the DEGT and the Vision Monitor.

An independent-samples t-test was conducted to compare glare scores in Metrovision and our glare test. There was a significant difference in the scores for Metrovision $(M=126.25$, $\mathrm{SD}=60.63)$ and our glare test $(\mathrm{M}=200.00, \mathrm{SD}=57.104) ; \mathrm{t}(46)=-4.338, \mathrm{p}<.001)$. Glare values obtained with DEGT are higher than those obtained with Vision Monitor with a MD of 73.7 arcmin. 


\section{Discussion}

The results of the present study demonstrate that DEGT is a valid method to test halo size. The correlation observed between the DEGT and the Vision Monitor is at a "high" level according to the Cohen effect sizes classification. The simple linear regression shows that the two tests shared $48,6 \%$ of variance. Furthermore, Bland-Altman analysis shows good agreement with a bias of 73 arcminutes. This bias could be related to the contrast settings of the optotypes which were designed so as not to have a ceiling effect while testing an antiglare system. To achieve this, the optotypes have been specified at a lower contrast than the ones in the Vision Monitor. This meant the DEGT was therefore efficient in distinguishing the different settings of an anti-glare device/system, with different levels of light transmission, without incurring ceiling or floor effects.

The results of this validity study show not only that the DEGT is a valid measure of disability glare but they also show the relevance of using a more ecologically specific measure of glare for this type of study. In fact, glare in the laboratory is evaluated one eye at a time whilst the DEGT is done in ecological conditions with both eyes open at the same time. In addition, the DEGT uses real headlamps to produce the glare source. As a result, this test takes into account the specificities of car headlights which differ according to the light spectrum, the shape of the beam, the spatial extent, etc.

This point is an advantage, in comparison with the clinical tests, knowing that these different characteristics also have an effect on the level of discomfort. Moreover, due to the use of headlights, the illumination of the optotypes on the canvas is not uniform and the contrast of the optotypes is different from that used in Metrovision. Thus, even though there is a good correlation and agreement between the two types of test, we find that this correlation is not perfect, and we observe that only half of the variance for our test is explained by the laboratory test. This indicates that our field test has a real interest since it allows a more efficient measurement of real driving glare as compared to the laboratory tests. 
Climatic conditions can have an effect on the visibility of optotypes. This means glare tests realized outdoors are subject to a certain level of variability due in particular to meteorological conditions which can alter to some degree the measurement (lightly foggy weather, rainy weather, clear or cloudy skies). It is therefore necessary, when doing the test, to have identical conditions for each participant. Indoor testing could be possible to control for those effects. It is also important to state that the illumination of the optotypes, produced by the headlights of the participants' car, is not totally homogeneous. However, on the other hand, this potential variability does not hinder the evaluation of a system or device since such studies are performed with a repeated measures protocol, where the two compared scores come from the same participant and are therefore collected under the same environmental conditions.

Furthermore, DEGT is easier to implement than field tests based on reaction time, since it only requires a covered space without light pollution. In addition this test, used to evaluate an anti-glare device, provides objective data on the size of the halo produced by the glare, and the subsequent benefit of ADAS that are directly understandable and interpretable.

One of the limitations is that driving is essentially a dynamic activity and that DEGT takes place under static conditions. Indeed, while driving, the driver may be forced to perceive, to analyse and to make a decision in a very short period of time. However, the participants on the DEGT can, to a certain extent, take their time to answer. It might be interesting to adapt this test to introduce a time constraint in the reading of otptotypes. Another limitation of the study is that optotypes are not ecological in the driving context. Their form is relatively different from what the driver encounters in their visual environment. However, they have the advantage of allowing a standardization of the test.

\section{Conclusions}


The Driver Ecological Glare Test provides a reliable and accurate measure of the halo size produced by headlamps in a driving configuration. Furthermore, it allows the evaluation of the benefits of an antiglare device for drivers in an ecological situation. 


\section{References}

Akashi, Y., \& Rea, M. (2001). The effect of oncoming headlight glare on peripheral detection under a mesopic light level. In Proceedings of the Symposium on Progress in Automobile Lighting, Herbert Utz Verlag GmbH, Darmstadt, Germany.

Bullough, J. D., Fu, Z., \& Van Derlofske, J. (2002). Discomfort and Disability Glare From Halogen and HID Headlamp Systems. In SAE (Ed.), SAE 2002 World Congress. Detroit,. MI.

Bullough, J., Skinner, N., Pysar, R., Radetsky, L., Smith, A., \& Rea, M. (2008). Nighttime glare and driving performance: Research findings. Washington, DC.

Clark, J. (2004). Nighttime Driving Evaluation of the Effects of Disability and Discomfort Glare from Various Headlamps under Low and High Light Adaptation Levels. Virginia Polytechnic Institute and State University.

De Boer, J. B. (1967). Visual perception in road traffic and the field of vision of the motorist (Public Lig). Eindhoven, Netherlands: Philips Technical Library.

Mainster, M. A., \& Timberlake, G. T. (2003). Why HID headlights bother older drivers. Br J Ophthalmol, 87, 113-117.

Miller, D., \& Benedek, G. (1973). Intraocular Light Scattering: Theory and Clinical Application (pp. 82-87). Springfield, IL: Charles C. Thomas.

Palomo-Álvarez, C., \& Puell, M. C. (2015). Capacity of straylight and disk halo size to diagnose cataract. Journal of Cataract \& Refractive Surgery, 41(10), 2069-2074. https://doi.org/10.1016/J.JCRS.2015.10.047

Plainis, S., Murray, I. J., \& Charman, W. N. (2005). The role of retinal adaptation in night driving. Optometry and Vision Science, 82(8), 682-8.

Puell, M. C., Pérez-Carrasco, M. J., Barrio, A., Antona, B., \& Palomo-Alvarez, C. (2013). Normal Values for the Size of a Halo Produced by a Glare Source. Journal of Refractive 
Surgery, 29(9), 618-622. https://doi.org/10.3928/1081597X-20130819-03

Puell, M. C., Pérez-Carrasco, M. J., Palomo-Alvarez, C., Antona, B., \& Barrio, A. (2014). Relationship between halo size and forward light scatter. The British Journal of Ophthalmology, 98(10), 1389-92. https://doi.org/10.1136/bjophthalmol-2014-304872

Ranney, T., Masalonis, A., \& Simmons, L. (1996). Immediate and Long-Term Effects of Glare from Following Vehicles on Target Detection in Driving Simulator. Transportation Research Record: Journal of the Transportation Research Board, 1550, 16-22. https://doi.org/10.3141/1550-03

Reagan, I. J., \& Brumbelow, M. L. (2017). Drivers' detection of roadside targets when driving vehicles with three headlight systems during high beam activation. Accident Analysis \& Prevention, 99, 44-50. https://doi.org/10.1016/J.AAP.2016.09.021

Theeuwes, J., Alferdinck, J. W. A. M., \& Perel, M. (2002). Relation Between Glare and Driving Performance. Human Factors: The Journal of the Human Factors and Ergonomics Society, 44(1), 95-107. https://doi.org/10.1518/0018720024494775

van den Berg, T. J. T. P., (René) van Rijn, L. J., Kaper-Bongers, R., Vonhoff, D. J. J., VölkerDieben, H. J. J., Grabner, G., ... Gamer, D. (2009). Disability Glare in the Aging Eye. Assessment and Impact on Driving. Journal of Optometry, 2(3), 112-118. https://doi.org/10.3921/joptom.2009.112

Vos, J. J. (2003). On the cause of disability glare and its dependence on glare angle, age and ocular pigmentation. Clin Exp Optom, 86(6), 363-370. Retrieved from http://clearlyvisiblepresentations.homestead.com/On_the_cause_of_disability_glare.pdf

Whetsel Borzendowski, S. A., Stafford Sewall, A. A., Rosopa, P. J., \& Tyrrell, R. A. (2015). Drivers' judgments of the effect of headlight glare on their ability to see pedestrians at night. Journal of Safety Research, 53, 31-37. https://doi.org/10.1016/j.jsr.2015.03.001

Wördenweber, B., Wallaschek, J., Boyce, P., \& Hoffman, D. (2007). Automotive lighting and 
human vision. Automotive Lighting and Human Vision. https://doi.org/10.1007/978-3$540-36697-3$ 